\title{
LA PRIMERA REFORMA UNIVERSITARIA EN SAN MARCOS (1571)
}

(Humilde apostilla en homenaje al $455^{\circ}$ aniversario de la Universidad de San Marcos)

\author{
Juan Alberto Campos Lama \\ Docente de la Facultadi de Ciencias Contables
}

\begin{abstract}
RESUMEN
No había cumplido veinte años de vida nuestra universidad, cuando los estremecimientos y preocupaciones de un movimiento reformista se hicieron sentir, llenando de honda preocupación a los miembros del claustro universitario y de interminable comidilla para esa Lima que terminaba la sexta década del siglo XVI.

Esta reforma fue de tan enorme trascendencia, pudiéndose decir, desde la perspectiva que nos da el tiempo pasado, que en ella San Marcos se jugó la vida, como centro esparcidor de cultura y semillero de ideas capaces de transformar favorablemente a una sociedad.

El resultado final de la reforma, que duró algunos siglos en su crisis, fue secularizar a la Universidad, ponerla dentro de las corrientes intelectuales y necesidades materiales que reinaban en el mundo y sustraerla al dominio de nuestros Padres Fundadores, los frailes dominicos. «Desenclaustrarla», sacarla de los claustros conventuales.
\end{abstract}

Palabras clave: Reforma en San Marcos, evolución institucional.

\section{INTRODUCCIÓN}

Cuando Constantino «El Grande», en 313, mediante el edicto de Milán reconoció para todo el imperio romano la libertad religiosa, empieza, oficialmente al menos, la época que la historia conoce como el Pensamiento Patrístico, que marcaría por milenios el pensamiento de Occidente. (1) Época en la cual las escuelas y escritores eclesiásticos, aprovechando la franquicia que les concedía el emperador romano, se expandieron por todo el mundo conocido.
Posteriormente, son cerradas por el Emperador Justiniano, en 529, las denominadas Escuelas de Atenas, últimos reductos del languideciente pensamiento griego, se entroniza así una concepción que pone a Dios como centro del Universo, regula las relaciones del hombre con el Ser divino, estableciendo leyes y jerarquías que van mucho más allá de la exigencia religiosa y condicionó, bajo diversos nombres, la forma de vida del ser humano por más de mil años.

Vayamos a la Lima del año 1569. Empezaba a declinar y sin lentitud, el

1 RAEMAEKER, Louis de. Introducción a la Filosofia. Editorial Gredos, Madrid, 1969, p. 106 y ss. 
importante y decisivo rol que significó para el dominio español en Hispanoamérica la fundación de San Marcos con prerrogativas y categoría igual que la Universidad de Salamanca. La Universidad se había mantenido al margen de los cambios y transformaciones que sufría el mundo en el siglo y refugiada bajo rígidos conceptos escolásticos, llevaba una vida conventual y declinaba su importancia para el gobierno virreinal, como centro proveedor de funcionarios que el manejo de la cosa pública y privada reclamaba.

No olvidemos que el siglo XVI caracterizó el pleno establecimiento del poderío español en el mundo, gracias a la obra del Emperador Carlos V, a quien debemos nuestra fundación; por la ampliación de la expansión territorial de Francia e Inglaterra, más allá de sus costas, por el alumbrar de genios como Giordano Bruno, muerto en defensa de sus principios matemáticos, éticos y filosóficos; y Galileo, viviendo para establecer esos mismos principios científicos. Es en este siglo que se dio la Gran Reforma religiosa, cuando el Papado, hasta hacía poco eje indiscutible del mundo social, político y religioso, era cuestionada totalmente como institución infalible; Nicolás Copérnico, quien a lo largo de cuarenta años de su hermosa y abnegada vida, había establecido los principios científicos que demostraban el errabundo transitar de los astros por el cielo, a través de sus Seis libros sobre las revoluciones de las esferas celestes, hacía que Claudio Ptolomeo y la concepción geocéntrica del Universo empezaran inexorable destino hacia el vertedero de la Historia; luego Johannes Kepler, hombre que supo aunar magistralmente imaginación y razonamiento, afirma definitivamente con sus lentes astronómicas, el acierto teórico de Copérnico.

En este siglo XVI, Leonardo da Vinci, a la sombra del Papado y lejos de los fuegos de la Inquisición, muestra su calidad como precursor de la "... técnica y ciencia modernas.... $\nu^{2}$. Es fácil percatarse así que el XVI fue un siglo pleno de transformaciones conceptuales, creaciones y aventuras. A cuál más positiva para la humanidad entera.

\section{¿Y, EN NUESTRA AMADA SAN MARCOS?}

Protegida por los altos y cerrados muros del Convento del Rosario, el Estudio General, como se llamaba entonces a la Universidad, tenía sus alas férreamente sujetas por la fuerza de la Teología, su diario exigente ejercicio y celosa aplicación que de la misma hacían los Padres dominicos. Son hartamente explicativas sobre este particular las premonitorias palabras de nuestro preclaro fundador, Fray Tomás de San Martín, cuando sentencia ante los Reyes Católicos que «... existe aparejo conveniente para fundar el Estudio General en la casa de los dominicos.... ${ }^{3}$.

La razón efectiva de la fundación de nuestra Alma Mater recae en la necesidad que tenía el gobierno español de dotar con letrados y magistrados, así como religiosos, las creciente necesidades de su imperio, considerando a Lima como uno de sus más importantes puntos de acción, siendo como

2 SALVAT. Historia Universal. Lima, Editor Orbis ventures S.A.C. 2005, t. 13, pp. 381/407.

3 EGUIGUREN, Luis Antonio. La Universidad Nacional Mayor. de San Marcos. Editado por encargo del Consejo Universitario de San Marcos, con ocasión del IV Centenario de su fundación. Lima, 1951, pp. 17/31. 
era «... el centro comercial más poderoso de la Colonia...». No olvidemos que al Callao, puerto de Lima, llegaban todas las mercaderías que enviaba la metrópoli para ser distribuías a todo el Virreinato del Perú y a sus dependencias administrativas, que abarcaban casi toda la parte del continente meridional. A El Callao llegaban mulas y acémilas ahítas de plata y oro para ser enviadas a España.

Para los dominicos, la necesidad era menos pegada en la tierra. La propagación de la Fe. Es allí donde empieza, a nuestro juicio, la primera fisura entre el poder seglar y el poder religioso que los frailes ejercían sobre la naciente institución universitaria.

Su obra en este orden es bastante significativa y enaltecedora. Allí están para corroborar nuestro aserto $E / A$ rte de la lengua general Quechua, obra de ese gran Rector que fuera Fray Domingo de Santo Tomás, luminosa figura de nuestros claustros sanmarquinos, gran defensor de indios y oprimidos. Este libro fue publicado, aparte de ser usado por los misioneros y evangelizadores; para que el Rey sepa «... clara y manifiestamente cuan falso es lo que mucho os ban querido persuadir ser los naturales de los reinos del Perú bárbaros e indignos de ser tratados con la libertady suavidad que los demás vasallos"'. Expresión que disgustaría mucho, pero mucho, a los encomenderos que veían en los nativos de estos reinos solo al más vil objeto de esclavitud.

Siempre recordando a L. A. Eguiguren, en cuya obra entramos a saco; merece citemos a otro notable Rector, Fray Alonso de la Cerda quien, desde el Cusco reclama al Rey, nada menos, para hablarle de los «... derechos y obligaciones de los indios asi como de los encomenderos...", reclamo que expone ante el soberano español el despiadado trato, verdaderamente genocida, que los encomenderos propinaban a los nativos en minas y obrajes. Bien vemos que eran otros tiempos y que nuestros rectores estaban acuñados en moldes tales que permitían desafiasen y enfrentasen a los más poderosos, con tal de cumplir y hacer saber sus humanitarios principios; aún a riesgo de la propia vida, conforme sabremos líneas delante. Desdichadamente para nuestra universidad, pareciera como si el molde que sirviera para troquelar a estos prioresrectores, se perdió en los meandros y vericuetos de la Historia.

\section{LA ENSEÑANZA DURANTE EL PERÍODO DOMINICO}

En la índole educadora, el Estudio General se hallaba casi asfixiado «... bajo la sombra del Convento del Rosarion, cerrado intransigentemente a toda influencia exterior, defendidas celosa y agresivamente sus prerrogativas y propiciando cada día un choque mayor con la sociedad circundante, choque cuyas consecuencias serían terribles para la Orden Dominica. Las lecciones eran impartidas por los propios frailes, quienes no cobraban estipendio alguno. Maestros seglares, como Martín de Ugalde, sí percibían paga por sus clases. El Rector, que mantenía al mismo tiempo el cargo de Prior del Convento del Rosario, nombraba, según su omnímoda voluntad a los profesores para las respectivas cátedras. Diremos, abre-viando, que la Universidad vivía verdadero espíritu confesional.

4 EGUIGUREN, Luis Antonio. Ob. cit. p. 37. 


\section{UN RECTOR QUEMADO VIVO}

Dentro de la estirpe de aguerridos hombres enemigos del cruel sistema de explotación humana que caracterizaba al virreinato, se hallaba Fray Francisco de la Cruz, a quien el historiador señala como siendo "...bombre de austera conducta...». Con suma frecuencia abandonaba sus obligaciones rectoras, para ir a los sitios donde mayor era el abuso contra los indios. Charcas, y Chucuito lo vieron llegar en varias oportunidades, levantada su figura, altivo y desafiante, enrostraba a los encomenderos la iniquidad de su conducta.

Este comportamiento y esta condena contra el sistema opresor no podían durar mucho. Se fragua un escándalo y se mezcla en el mismo a Fray Francisco, interviene el Santo Oficio (la Inquisición), que de santo tenía muy poco y símucho de oficio. Juzgado nuestro combativo rector, es condenado a ser quemado vivo en uno de los tristes $A$ utos de $F e$, que alumbraran tan siniestramente a la Colonia. Esto ocurría el año 1569. Como es de suponer el escándalo que se desató en la Lima beata, santurrona, chismosa y cucufata, alcanzó magnitudes astronómicas y sirvió para debilitar aún más la posición de los dominicos frente a la sociedad laica.

La ciudad y el virreinato por entero estaban privados de grandes motivos de distracción, los espectáculos de la época se reducían a eventuales puestas en escena de comedias, con motivo de las festividades religiosas $^{5}$, circunstanciales corridas de toros, algún picante episodio de la vida palaciega, riña de gallos. Es fácil comprender cómo, con tales necesidades de diversiones periódicas, cuan enormes serían el efecto y estruendo que en la opinión pública causó la quema en una hoguera de un Rector de San Marcos, nada menos, por más altos $\mathbf{y}$ elevados motivos que inspiraron a los autores de tal acción.

\section{CAUSAS INMEDIATAS DE LA REFORMA}

En abril del año 1568 es cuando llegaron los Padres jesuitas a Lima; desde esa fecha, hasta nuestros días, la obra educadora de estos hombres sería de singular importancia para el desarrollo del Perú. Su primer aposento fue en el Convento del Rosario, permiso que les fuera concedido por el Rector Fray de la Cruz. Los jesuitas estaban encabezados por Fray Jerónimo Ruiz del Portillo, acompañado por siete sacerdotes de su Orden, mostrando suma habilidad, aprovecharon bien, la generosa hospitalidad de los dominicos. Con el tiempo, sostiene Eguiguren, «... losjesuitas tendrian en sus manos el monopolio de la enseñanza en el Virreinato». Expresado este hecho en otros conceptos y palabras, podemos decir que el poder español ya tenía con los jesuitas otras posibilidades para proveer las necesidades educativas de la población a su cargo.

Conforme citamos, la trágica muerte del Rector Fray Francisco de la Cruz, fue un golpe del cual no se recuperaría la Orden dominica. El escándalo, los intereses externos e internos al Convento, contribuyeron para que el poder seglar aprovechase oportunamente el suceso. No olvidemos que al frente del poder se hallaba nada menos que esa gigantesca figura que fue el Virrey Toledo.

5 LOHMAN VILLENA, Guillermo. «El Teatro en el Perú virreinal...». En: Serie Estudios de Teatro Peruano. Servicio de Publicaciones del Departamento de Teatro. UNMSM, Feb. de 1960. 
En las postrimerías de esta agitada e importante etapa de la vida de San Marcos, accede al Rectorado Fray Alonso Guerra, persona de carácter y temple poco aptos para ejercer su cargo en las difíciles situaciones que le tocaría enfrentar, empieza el declive administrativo, el Rector nombraba catedráticos según su libre albedrio, y las cosas llegaron a extremos tales que el portero se permitía determinar que alumnos podían ingresar a clases.

A todas las causales ya mencionadas, debemos añadir el creciente número de doctores, funcionarios e intelectuales que llegaban a Lima desde la Península, y cuya presencia servía para contrastar vivamente la diferencia entre sus capacidades y las ostentadas por los profesionales que salían de los Estudios Generales

Dentro del claustro, los doctores laicos mantenían sorda lucha con sus pares religiosos, pues constataban el detrimento hacia el que rodaba la institución. Los profesores laicos se habían graduado en Salamanca y demás universidades españolas, quienes no podían aceptar, y no por razones de fe precisamente, que una institución como nuestros Estudios Generales estuviese sometida al dictado confesional, al margen delos avances de su época. La historia registra algunos nombres de dichos reformistas que desde la cátedra ayudaron a salvar la Universidad. Recordemos con unción a hombres con la talla y prestigios de: Pedro Fernández Valenzuela, Gabriel Loarte, Diego de Zúniga, Ramírez de Cartagena, Germán Vásquez de Fajardo, Gaspar de Meneses, Marco de Lucio, Sánchez Renedo, Francisco Franco, López Guarnido y Cosme Carrillo; hombres que con sus luces y amor por el estudio prestigiaron su paso por las páginas de la historia sanmarquina.
Esta oposición interna fue, después, gravitante para la posterior intervención externa. Los docentes laicos unían protestas y quejas a las proferidas a viva voz, en términos poco académicos, fuera del claustro, toda la inmensa clientela que para el gobierno de la época constituían los burócratas del Cabildo, de la Real Audiencia y demás funcionarios del Estado, al igual que los frailes de otras órdenes. Clientela y circunstancias que no permitían retardar mucho tiempo más el cambio, ya sea bien por intereses egoistas o por mandato de exigencias propias del buen devenir de la historia, obligaban a que otras manos tuviesen esa fuente de poder que era nuestra naciente universidad. Ocasión y aliados que supo aprovechar, con gran visión histórica, ese fino estratega político y ejemplo de estadistas que fuera el Virrey Francisco de Toledo.

\section{CONSECUENCIAS DE LA REFORMA}

En el ordenamiento procesal, la reforma se inició con un memorial presentado ante la Real Audiencia por los maestros universitarios "...Meneses, Lucio, Cosme Carrillo, Lópeq Guarnido y otros...», solicitando la convocatoria de un Claustro Pleno, en el cual se debería nombrar libremente al nuevo Rector vista; entre otros considerandos, la mala gestión del rector Fray Alonso. Esto significaba simple y llanamente sacar del claustro a los Estudios Generales y colocarlos directamente al servicio de la sociedad virreinal pues, en lo político, la Universidad estaría regida solo por las leyes y disposiciones emanadas del poder civil, y a partir de ese momento se colocaba bajo el Real Patronato. Sin ninguna otra injerencia. 
Esta solicitud era una verdadera revolución, pues se estaba arrancando de las manos de una poderosa orden religiosa a su presea más valiosa, la Universidad, a través de la cual modelaba espíritus y adquiría poderes que se extendían hasta dimensiones insospechadas. Pero los aires eran de fronda y los vientos traían cosas malas para nuestros Padres Fundadores. La solicitud para la realización del Claustro Pleno fue respaldada por la casi totalidad de la sociedad limeña, sintiendo la necesidad imperiosa de contar con un adecuado centro de educación superior.

Consolidando esta petición, la Real Audiencia promulga el 11 de mayo de 1571 - simbólicamente vísperas de nuestro vigésimo aniversario fundacional- el proveído que autoriza la realización de dicho claustro para elegir a nuestro Primer Rector Laico. El Pleno acuerda otorgar esta hermosa distinción al Doctor Pedro Fernández Valenzuela, Decano de Leyes, quien sería el encargado abrir las puertas de San Marcos a la ilustración, a las corrientes intelectuales más en boga por el mundo y rumbear nuestra universidad hacia los destinos llenos de gloria que llenan páginas de la historia nacional; ése, y no o-" fue el significado de nuestra Primer. Reforma Universitaria. Acotemos que .: historiadores de la Orden de los Dominu : borraron de sus trabajos el nombre del pame rector laico que tuviera nuestra universıaad Fue recién en el siglo $\mathrm{XX}$ que supimos a don Pedro Fernández Valenzuela $\mathbf{v} \mathbf{s}$ ejemplar obra a favor de San Marcos" Rindamos obligado y fervoroso homenaie a este maestro.

\section{REFERENCIAS}

RAEMAEKER, Louis de. Introducción a la Filosofia. Madrid, Editorial Gredos, 1969. Pp. 106 y ss.

SALVAT. Historia Universal. Lima, Editor Orbis ventures S.A.C., 2005, t. XIII, pp. $381 / 407$.

EGUIGIREN, Luis Antonio. La Universidaa Nacional Mayor de San Marcos. Editado por encargo del Consejo Universitario de San Marcos, con ocasión del IV Centenario de su fundación. Lima, 1951, pp. $17 / 31$.

6 EGUIGUREN, Luis Antonio. Ob.cit.p. 49. 